\title{
PENGARUH BRAND IMAGE, PRICE DAN TRUST TERHADAP PURCHASE INTENTION PEMESANAN KAMAR DI HOTEL IBIS SECARA ONLINE
}

\author{
Selvi Agustin \\ Program Studi Magister Manajemen Universitas Tarumanagara \\ (selviagust@yahoo.com)
}

\begin{abstract}
This research was conducted to analyze the influence of brand image, price and trust toward purchase intention of room booking at Ibis hotel via online method. Independent variables that were researched are brand image, price and trust. Meanwhile, dependent variables that were researched is purchase intention. The population that was researched is consumers who have stayed at Ibis hotel and used online booking method. Sampling used nonprobability method with nonprobability sampling. Data collection method used questionnaires which were distributed to 135 respondents who have stayed at Ibis hotel and used online booking method. Data analysis technique that was used is double regression analysis. The analysis result shows that there is an influence from price and trust toward purchase intention. However there is no influence from brand image toward purchase intention and the impact of brand image it is not significant. This research result is expected to be able to be used as a reference for online hotel booking marketer in Indonesia in order to attract tourists when they use online hotel booking.
\end{abstract}

Keywords: brand image, price, trust, purchase intention, online hotel booking, Hotel Ibis

\section{PENDAHULUAN}

Perkembangan ilmu teknologi dan informasi dari zaman ke zaman berkembang semakin pesat khususnya pada media internet yang memberikan banyak manfaat bagi para pengguna. Di Indonesia, penggunaan internet tahun 2017 telah mencapai 143,26 juta jiwa. Angka tersebut meningkat dibandingkan pada tahun sebelumnya, yakni tahun 2016 yang tercatat mencapai 132,7 juta jiwa. Data tersebut merupakan hasil survei yang dilakukan oleh Asosiasi Penyelenggara Jasa Internet Indonesia.

Saat ini banyak agen pariwisata yang memberikan pelayanan untuk tiket pesawat dan hotel melalui website. Hal ini ditunjang dari dengan keadaan bahwa Indonesia menduduki peringkat ke empat dalam industri pariwisata di negara ASEAN, posisi pertama diduduki oleh negara Thailaind, posisi kedua diduduki oleh negara Malaysia dan posisi ketiga oleh negara Singapura.sepanjang tahun 2015, hampir 30 juta orang wisatawan asing mengunjungi Thailand, lalu selanjutnya Malaysia dan Singapura, masing-masing dengan 25 juta dan 15 juta wisatawan 
mancanegara dalam setahun. Sementara Indonesia berada di posisi ke- 4 dengan 10 juta wisatawan.

Dalam bisnis pariwisata dan perhotelan brand image merupakan penentu yang mempengaruhi keputusan pembelian. Menurut Simonian (2012 dalam Lien et al., 2015), yang menyatakan bahawa brand image membawa pengaruh pada perilaku konsumen dalam keputusan pembelian.Membangun sebuah trust merupakan salah satu dari faktor yang menentukan suksesnya sebuah penyedia jasa (Kim, Xu \& Gupta, 2012). Begitupula dengan harga, harga mendorong konsumen untuk memutuskan membeli produk (Alfred et al., 2015). Hal ini didukung oleh pernyataan Ling bin et al., (2011 dalam Lien et al., 2015) faktor kepercayaan merupakan faktor yang penting bagi konsumen yang akan mempengaruhi keputusan pembelian.

Adapun objek yang dipilih dalam penelitian online hotel booking kali ini adalah Hotel Ibis. Hotel Ibis dikelola oleh Accor. Accor Hotels, operator hotel terbesar di Asia Pasifik dan Indonesia. Hotel Ibis termasuk di dalam kelas brand ekonomi (budget).

\section{TUJUAN PENELITIAN}

Tujuan dari penelitian ini, berdasarkan rumusan masalah yang telah dikemukakan sebelumnya maka penelitian ini memiliki tujuan adalah untuk mengetahui apakah brand image memiliki pengaruh terhadap purchase intention, untuk mengetahui apakah price memiliki pengaruh terhadap purchase intention, untuk mengetahui apakah trust memiliki pengaruh terhadap purchase intention.

\section{MANFAAT PENELITIAN}

Manfaat penelitian, hasil penelitian yang dilakukan oleh peneliti diharapkan dapat memberikan kontribusi yang baik kepada berbagai pihak yakni secara akademis adalah agar penelitian ini diharapkan dapat menambah wawasan, pengetahuan penulis dan menambah ilmu baik dalam teori maupun praktek tentang pengaruh brand image, price, dan trust terhadap purchase intention pemesanan hotel secara online. Kedua, agar penelitian ini dapat digunakan sebagai masukan dan referensi bagi peneliti lain yang sejenis. Secara praktis, hasil penelitian diharapkan dapat memberikan masukan informasi tentang dampak brand image, price, dan trust terhadap purchase intention pemesanan hotel secara online sehingga diharapkan bermanfaat bagi hotel Ibis dan hotel lain yang sejenis.

\section{LANDASAN TEORI}

Menurut Kotler \& Keller (2009:258) brand image adalah produk atau jasa yang dimensinya mendiferensiasikan merek tersebut dengan

beberapa cara dari produk atau jasa lainnya yang dirancang untuk memuaskan kebutuhan yang sama.

Sedangkan menurut Buchari Alma (2011:169) meyebutkan bahwa price adalah sebagai nilai suatu barang yang dinyatakan dengan bentuk uang.

Kepercayaan adalah salah satu fitur utama hubungan pembelipenjual. Kepercayaan mengacu pada sebuah keyakinan positif tentang keandalan dan ketergantungan seseorang atau sebuah benda (Everard \& Galletta, 2006). 


\section{Pengaruh brand image terhadap purchase intention}

Brand Image adalah isyarat ekstrinsik untuk evaluasi harga produk / jasa dan hasil brand image yang lebih baik dengan harga yang lebih tinggi (Grewal et al.,1998). Sebuah brand image yang baik akan memberikan pengaruh kepada kepercayaan konsumen akan sebuah produk dan pada akhirnya akan menimbukan keputusan pembelian oleh konsumen. Merek dengan harga yang wajar akan membuat konsumen memiliki niat lebih besar untuk membeli produk ataupun jasa (Dodds et al., 1991; Kim et al., 2012).

\section{H1: Brand image memiliki pengaruh signifikan terhadap purchase intention}

\section{Pengaruh price terhadap purchase intention}

Di industri perhotelan, hasil yang wajar menghasilkan lebih banyak nilai yang dirasakan oleh pelanggan (Lee, 2012) dan meningkatkan niat membeli oleh konsumen (Chiang \& Jang, 2007). Dalam studi ritel, harga lebih rendah dan promosi yang dilakukan terbukti sangat meningkatkan persepsi nilai belanja konsumen (Yoon et al., 2014).

H2: Price memiliki pengaruh signifikan terhadap purchase intention Pengaruh trust terhadap purchase intention

Bagi konsumen online, melakukan trasaksi dengan vendor secara online akan mempertimbangkan ketidakpastian dan resiko jika dibandingkan dengan transaksi jual beli secara tradisional. Dalam studi Ling (2011) juga mendukung hubungan positif antara trust dan purchase intention.

H3 : Trust memiliki pengaruh signifikan terhadap purchase intention

Dalam penelitian Lien et,al.,(2015) mengemukakan adanya hubungan antara brand image, price dan trust terhadap purchase intention. Dalam peneliitian ini menunjukan bahwa brand image dan price memiliki pengaruh terhadap purchase intention. Menurut penelitian Arman, et al.,(2011) menyatakan bahwa trust memiliki pengaruh terhadap purchase intention. Menurut Alfred et,al., (2015) menyatakan bahwa price memiliki pengaruh terhadap purchase intention. Menurut Agheykan et, al.,(2012) brand image berpengaruh pada pembelian konsumen secara online. Dari paparan jurnal di atas, maka menghasilkan kerangka pemikiran sebagai berikut :'

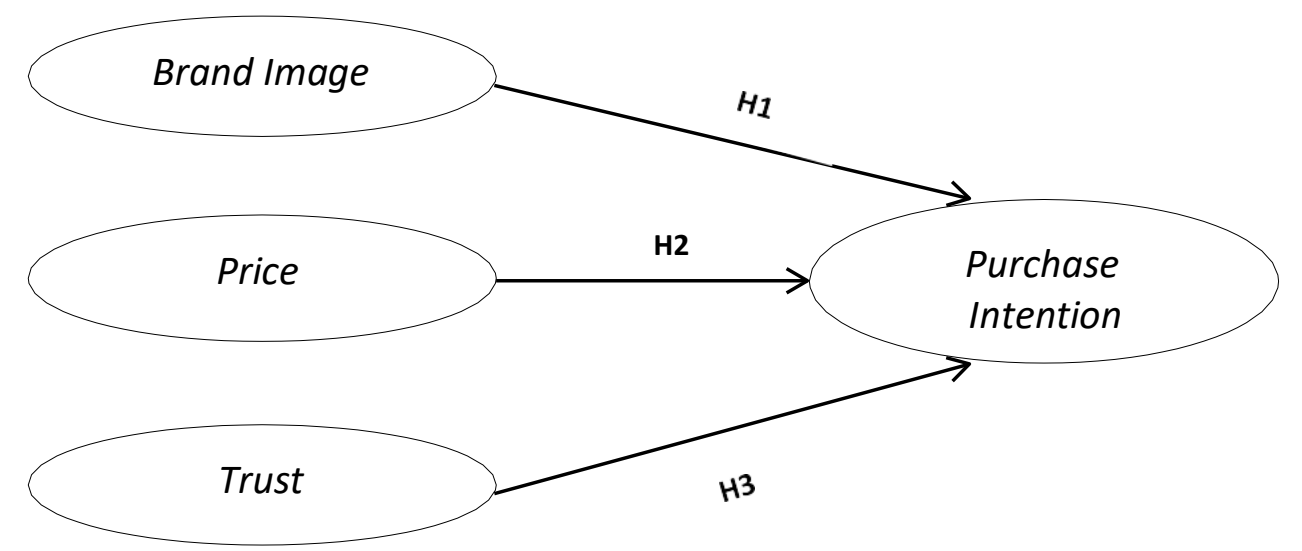




\section{METODE PENELITIAN}

Riset yang digunakan dalam penelitian ini yaitu kausal (sebab akibat) dan menggunakan alat bantu kuesioner kepada responden untuk memperoleh data yang dibutuhkan dengan tujuan untuk menganalisis hubungan antara satu variabel dengan variabel yang lainnya atau bagaimana suatu variabel mempengaruhi variabel lainnya (Sarwono, 2005). Penelitian ini memakai pendekatan kuantitatif di mana pendekatan ini digunakan untuk mengukur seberapa besar informasi yang didapatkan bukan pemahaman mendalam tentang informasi yang dipakai untuk melihat masalah yang akan diteliti (Malhotra, 2012).

\section{Populasi dan Metode Pengambilan Sampel.}

Populasi dalam penelitian ini adalah seluruh responden yang tinggal di Jakarta, pernah melakukan pemesanan kamar hotel secara online dan menginap di hotel Ibis di daerah Pulau Jawa, Pulau Bali dan Pulau Sumatera. Ukuran sampel yang digunakan pada penelitian ini adalah 135 responden. Metode pengambilan sampel yang digunakan adalah non-probability sampling yaitu , yaitu teknik pengambilan sampel di mana sampel yang diambil didasarkan pada pertimbangan peneliti (Zikmund, 2003).

Dari hasil penelitian ditemukan bahwa diketahui bahwa karakteristik konsumen mayoritas laki-laki, berusia antara 33 - 43 tahun, dengan pekerjaan sebagai pegawai swasta, kisaran penghasilan Rp 7.000 .000 - 12..000.000,-, dan website yang sering digunakan untuk pemesanan kamar secara online adalah Traveloka.

\section{Variabel dan Pengukuran.}

Pada penelitian ini, variabel brand image, price dan trust adalah variabel independen, sedangkan purchase intention adalah variabel dependen. Untuk mengukur variabel ini, menggunakan beberapa instrument yang diadaptasi dari studi penelitian terdahulu. Skala pengukuran yang digunakan dalam penelitian ini adalah Likert Type Scale dengan 5 skala dengan 1 menunjukkan "sangat tidak setuju" dan 5 menunjukkan "sangat setuju". Dari hasil uji validitas dan reabilitas menunjukkan bahwa semua variabel yang digunakan pada penelitian ini adalah valid dan reliabel.

\begin{tabular}{|c|l|c|c|c|c|}
\hline & \multicolumn{1}{|c|}{ Hipotesis } & B & Sig & t & Kesimpulan \\
\hline H1 & $\begin{array}{l}\text { Brand image memiliki pengaruh } \\
\text { signifikan terhadap purchase } \\
\text { intention }\end{array}$ & .114 & 0.68 & 1.840 & Ditolak \\
\hline H2 & $\begin{array}{l}\text { Price memiliki pengaruh signifikan } \\
\text { terhadap purchase intention }\end{array}$ & .419 & .000 & 5.439 & Tidak Ditolak \\
\hline H3 & $\begin{array}{l}\text { Trust memiliki pengaruh signifikan } \\
\text { terhadap purchase intention }\end{array}$ & .330 & .003 & 3.082 & Tidak Ditolak \\
\hline
\end{tabular}

\section{Metode Analisis Data.}

Metode analis data yang digunakan adalah analisis regresi berganda. Sedangkan untuk uji asumsi seperti uji normalitas, uji multikolinieritas dan uji heteroskedastisitas telah dilakukan sebelumnya 
dan hasilnya menunjukan semua uji asumsi sudah terpenuhi. Pengujian dalam penelitian ini menggunakan program SPSS. Taraf signifikansi yang digunakan dalam penelitian ini adalah 0,05 .

\section{ANALISA DAN PEMBAHASAN}

Berdasarkan hasil pengujian hipotesis pertama menguji apakah brand image memiliki pengaruh signifikan terhadap purchase intention maka ditemukan bahwa hasil penelitian ini bertententangan dengan penelitian sebelumnya Lien et al., (2015) yang dilakukan dalam penelitian mengenai online hotel booking bahwa brand image menunjukan hasil yang signifikan dan berpengaruh purchase intention.. Pada penelitian ini, menunjukan bahwa brand image tidak memiliki pengaruh signifikan terhadap purchase intention. Pada pengujian hipotesis kedua, menguji apakah price memiliki pengaruh signifikan terhadap purchase intention. Hasil pengujian hipotesis tersebut sudah sesuai dengan penelitian sebelumnya yang menyatakan bahwa price berpengaruh positif terhadap purchase intention Lien et al., (2015). Hal ini sama seperti yang dikemukakan oleh Yoon et al.,(2014); Kim et al., (2012); Alfred, et al., (2015) di mana price memiliki pengaruh terhadap purchase intention. Berdasarkan hasil pengujian hipotesis ketiga menguji apakah trust memiliki pengaruh signifikan terhadap purchase intention, maka hasil pengujian ini ditemukan bahwa trust memiliki pengaruh signifikan terhadap purchase intention. Dalam penelitian ini trust memiliki pengaruh terhadap purchase intention, hal ini sama dengan yang dikemukakan oleh Ling et al., (2011) bahwa trust memiliki pengaruh terhadappurchase intention. Menurut Zhou et al., (2011) trust memiliki pengaruh signifikan terhadap purchase intention. Hal ini juga didukung oleh penelitian Arman et al.,(2011) yang mengemukakan bahwa trust memiliki pengaruh terhadap purchase intention. Sebaliknya menurut penelitian Lien et al.,(2015) trust tidak memiliki pengaruh signifikan terhadap purchase intention. Hal ini karena konsumen lebih melihat dari nilai dari harga yang diberikan.

\section{PENUTUP}

\section{Kesimpulan.}

Brand image tidak memiliki pengaruh signifikan terhadap purchase intention, price memiliki pengaruh signifikan terhadap purchase intention dan trust memiliki pengaruh terhadap purchase intention.

\section{Saran}

Terkait dengan hasil penelitian ini, maka peneliti akan memberikan beberapa saran yang sekiranya dapat bermanfaat bagi perusahaan dan bagi peneliti lain yaitu peneliti menyarankan agar Hotel Ibis menciptakan brand image yang lebih memukau, misalkan dengan meningkatkan keunggulan, kekuatan dan keunikan suatu sehingga akan membuat konsumen percaya tentang brand image perusahaan. Hotel Ibis juga dapat sering melakukan promosi iklan di media sosial dan jaringan internet, dengan demikian diharapkan menimbulkan peluang konsumen untuk mengenal brand Hotel Ibis. Bagi peneliti lain, disarankan agar memperluas jangkauan pengambilan sampel dan cakupan wilayah, 
sehingga dapat memperkuat dan melengkapi penelitian. Bagi peneliti lain, juga disarankan dapat dilakukan penelitian dengan variabel bebas lain, sehingga variabel yang mempengaruhi keputusan pembelian dapat teridentifikasi lebih banyak lagi dari penelitian terdahulu yang belum sempat diteliti dalam penelitian ini, sehingga dapat diketahui faktorfaktor lain yang mempengaruhi keputusan pembelian.

\section{DAFTAR PUSTAKA}

Aghekyan-Simonian, M., Forsythe, S., Kwon, W. S., \& Chattaraman, V. (2012). The role of product brand image and online store image on perceived risks and online purchase intentions for apparel. Journal of Retailing and Consumer Services, 19(3), 325e331.

Alfred, O. (2015). Influences of Price And Quality On Consumer Purchase Of Mobile Phone In The Kumasi Metropolis In Ghana A Comparative Study, Vol 1, 195-222.

APJII. (2017). Indonesia Internet Users. Laporan Asosiasi

Penyelenggara Jasa Internet Indonesia. Diakses pada tanggal 18 Maret 2017

Buchari, Alma. (2011). Manajemen Pemasaran dan Pemasaran Jasa. Bandung : Penerbit Alfabeta

Chiang, C. F., \& Jang, S. C. (2007). The effects of perceived price and brand image on value and purchase intentions: leisure travellers' attitudes toward online hotel booking. Journal of Hospitality and Leisure Marketing, 15(3), 49e69.

Galletta, D. F., and Everard, A. (2005). "How Presentation Flwas Affect Perceived Site

Jacob Weisberg, Dov Te'eni, Limor Arman, (2011),"Past purchase and intention to purchase in e- commerce: The mediation of social presence and trust", Internet Research, Vol. 21 Iss: 1 pp. 82 96

Kim, S. B., Sun, K.A., \& Kim, D. Y. (2013). The influence of consumer value- based factors on attitude behavioral intention in social commerce: the differences between high and low technology experience group . Journal of Travel \& Tourism Marketing, 30(le2), 108-125

Kim, S. B., Sun, K.A., \& Kim, D. Y. (2013). The influence of consumer value- based factors on attitude behavioral intention in social commerce: the differences between high and low technology experience group . Journal of Travel \& Tourism Marketing, 30(le2), 108-125

Kotler, Philip. T dan Keller, K.L. (2009). Marketing management. $6^{\text {th }}$ Edition. Pearson.

Lee, F. S. J. (2012). The consumer price-perceived quality heuristic on the hotel Review of Business Research, 12(1), 96e101 
Lien Che-Hui, Wen Min-Jye, Huang Li-Ching \& Wu Kuo Lung, (2015).

Online hotel booking: The effects of brand image , price, trust and value on purchase intentions. Asia Pasific Management Review (20), 210-218.

Malhotra, N. (2010). Marketing Research: An Applied Orientation (6 $6^{\text {th }}$ ed.). New Jersey: Pearson: Pearson Education Inc.

Sarwono, Jonathan (2005). Teori dan Praktek Riset Pemasaran dengan SPSS. CV Andi, Yogyakarta.

Sugiyono. (2012). Memahami Penelitian Kualitatif. Bandung : ALFABETA. Zhou, Weiguo F., \& Bauzhou Lu. (2011. Social presence, trust, and social commerce purchase intention: An empirical research. Computers in Human Behaviour, 56 (2016), 225 -337

Zikmund, William G. et.al. (2003). Customer Relationship Management Integrating Marketing Strategy and Information Technology. New Jersey: John Wiley and Sons 


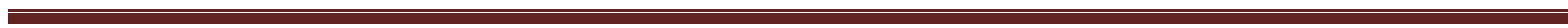
$\cdot$ 